Illinois State University

ISU ReD: Research and eData

Theses and Dissertations

$3-22-2021$

\title{
Exploring The Impact Of Utilizing Real Patients During Nutrition Counseling Training
}

Ashlyn R. Hayes

Illinois State University, hayesar1s@gmail.com

Follow this and additional works at: https://ir.library.illinoisstate.edu/etd

Part of the Nutrition Commons

\section{Recommended Citation}

Hayes, Ashlyn R., "Exploring The Impact Of Utilizing Real Patients During Nutrition Counseling Training" (2021). Theses and Dissertations. 1374.

https://ir.library.illinoisstate.edu/etd/1374

This Thesis is brought to you for free and open access by ISU ReD: Research and eData. It has been accepted for inclusion in Theses and Dissertations by an authorized administrator of ISU ReD: Research and eData. For more information, please contact ISUReD@ilstu.edu. 


\section{EXPLORING THE IMPACT OF UTILIZING REAL PATIENTS DURING NUTRITION COUNSELING TRAINING}

\section{ASHLYN R. HAYES}

\section{Pages}

The purpose of this study was to explore the educational advantages real patients can offer dietetic students in nutrition counseling training. In addition, this study observed the impact of training with real patients on dietetic students' nutrition counseling confidence. Six dietetic students were purposefully selected to participate in semi-structured individual interviews. Students expressed their opinions and experiences regarding their nutrition counseling training sessions with both simulated and real patients. Each interview was audio-recorded and later transcribed verbatim. Using a grounded theory approach, key themes were identified from the data. Findings from this study indicated that practicing nutrition counseling with real patients can help dietetic students develop confidence and professional skills that are crucial to the dietetics field. Incorporating both simulated and real nutrition counseling experience into dietetics curriculum can provide students with well-rounded opportunities for professional growth. KEYWORDS: nutrition counseling; real patients; simulated patients; dietetic students 


\title{
EXPLORING THE IMPACT OF UTILIZING REAL PATIENTS DURING NUTRITION COUNSELING TRAINING
}

\author{
ASHLYN R. HAYES
}

\author{
A Thesis Submitted in Partial \\ Fulfillment of the Requirements \\ for the Degree of \\ MASTER OF SCIENCE \\ Department of Family and Consumer Sciences \\ ILLINOIS STATE UNIVERSITY
}

2021 
(C) 2021 Ashlyn R. Hayes 


\section{EXPLORING THE IMPACT OF UTILIZING REAL PATIENTS DURING NUTRITION COUNSELING TRAINING}

ASHLYN R. HAYES

COMMITTEE MEMBERS:

Julie Schumacher, Co-Chair

Jennifer Banning, Co-Chair

Elke Altenburger 


\section{ACKNOWLEDGMENTS}

I wish to thank all the people who made the success of my graduate thesis possible. First, I would like to thank my devoted and supportive committee co-chair, Dr. Julie Schumacher, for her immeasurable encouragement, patience, and assistance throughout this project. Additionally, I wish to express my sincere gratitude for my co-chair, Dr. Jennifer Banning, and committee member, Dr. Elke Altenburger, for their analytical expertise and constructive feedback that have been crucial throughout the process of writing this thesis. I would like to extend my sincere gratitude to my study participants. Without their willingness to share their personal experiences with me, this study would not exist. Last, I wish to thank my incredible friends and family. Their unconditional love is invaluable, and I am eternally grateful for their tremendous support during this wonderful milestone in my academic career.

A. R. H. 


\section{CONTENTS}

Page

ACKNOWLEDGMENTS

CONTENTS

FIGURES

CHAPTER I: EXPLORING THE IMPACT OF UTILIZING REAL PATIENTS DURING

NUTRITION COUNSELING TRAINING 1

Introduction $\quad 1$

$\begin{array}{ll}\text { Methods } & 4\end{array}$

Participants and Recruitment 4

Nutrition Counseling Program 4

Data Collection $\quad 5$

$\begin{array}{ll}\text { Data Analysis } & 6\end{array}$

$\begin{array}{ll}\text { Findings } & 8\end{array}$

$\begin{array}{lr}\text { Overview } & 8\end{array}$

Real Counseling Experience Aids in Career Preparation 8

Opportunity to Increase Confidence $\quad 9$

Simulated Practice is Comfortable, but Limited 9

$\begin{array}{ll}\text { Nutrition Mission Lacking Participants } & 10\end{array}$

Discussion 11

$\begin{array}{ll}\text { Real Counseling Experience } & 11\end{array}$

$\begin{array}{ll}\text { Simulated Counseling Experience } & 12\end{array}$

$\begin{array}{ll}\text { Limitations and Strengths } & 13\end{array}$ 
$\begin{array}{ll}\text { Conclusion } & 14\end{array}$

$\begin{array}{ll}\text { CHAPTER II: EXTENDED REVIEW OF THE LITERATURE } & 17\end{array}$

Nutrition Counseling's Role in Managing Chronic Illness 17

Differences in Nutrition Counseling Competence 20

Nutrition Counseling Training Techniques 23

Nutrition Counseling Training with Real Patients 25

$\begin{array}{ll}\text { Gap in Literature } & 27\end{array}$

$\begin{array}{ll}\text { Conclusion } & 28\end{array}$

$\begin{array}{lr}\text { REFERENCES } & 29\end{array}$

APPENDIX A: CODE MAP FIGURE 35

APPENDIX B: INTERVIEW GUIDE 36

APPENDIX C: RESEARCH AND INTERVIEW QUESTION OUTLINE 37

$\begin{array}{ll}\text { APPENDIX D: CODE DEFINITIONS } & 38\end{array}$

APPENDIX E: RECRUITMENT EMAIL 39

$\begin{array}{ll}\text { APPENDIX F: INFORMED CONSENT } & 40\end{array}$ 


\section{FIGURES}

Figure $\quad$ Page

Code Map Illustrating Findings from Interviews with Dietetic Students

16 


\section{CHAPTER I: EXPLORING THE IMPACT OF UTILIZING REAL PATIENTS DURING}

\section{NUTRITION COUNSELING TRAINING}

\section{Introduction}

Nutrition counseling is a crucial component of a registered dietitian's career. This type of counseling helps patients form positive dietary habits and teaches them to manage a healthy lifestyle. Furthermore, numerous studies have demonstrated that nutrition counseling is a vital form of therapy in helping patients manage, and prevent, chronic illness (Hernández-Morante, Sánchez-Villazala, Cutillas, \& Fuentes, 2014; Ho et al., 2020; Schwartz, Rothpletz-Puglia, Denmark, \& Byham-Gray, 2014). Registered dietitians are expected to attain a higher competence in nutrition counseling than other healthcare professionals. Porter et al. (2019) insists the development of effective nutrition counseling skills is essential for dietetic students to successfully transition into professional practice.

The Accreditation Council for Education in Nutrition and Dietetics (ACEND) outlines a set of knowledge requirements for registered dietitian nutritionists, abbreviated as KRDN, dietetic students need to achieve prior to their completion of a Didactic Program in Dietetics (DPD). KRDN 3.3 states that, upon completion of the program, graduates are able to "demonstrate counseling and education methods to facilitate behavior change and enhance wellness for diverse individuals and groups" (ACEND, 2016). In order to corroborate with the counseling knowledge requirement, each DPD is required to design curriculum that incorporates principles of effective nutrition education and counseling techniques (ACEND, 2016). Curriculum tailored to this requirement often involves a combination of classroom lecture and hands-on learning. It is clear that learning effective nutrition counseling skills is a vital constituent of a dietetic student's education. That being the case, it is essential that dietetic 
students feel confident and competent in their nutrition counseling skills by the time they complete their training and begin their careers.

Patient simulations have been widely used as an educational tool during nutrition counseling training for dietetic students (Buchholz, Vanderleest, MacMartin, Prescod, \& Wilson, 2020). These simulations are designed to replace and mimic real experiences through the use of case studies, peer role-play, digital mannequins, and simulated patients played by actors (Gaba, 2004). Past studies have demonstrated that patient simulations help students gain confidence and increase students' knowledge and preparation to enter the workforce (Buchholz et al., 2020; Henry, Duellman, \& Smith, 2009; Miles, Friary, Jackson, Sekula, \& Braakhuis, 2016). Although a growing number of studies have observed dietetic students' nutrition counseling competence and confidence development following their experiences with simulated patients, few studies have observed the outcomes of dietetic students practicing nutrition counseling with real patients.

One study explained that utilizing real patients for nutrition counseling training can be a problematic method due to the unpredictability of clients presenting with "complex diet and medical histories" (Schwartz et al., 2014). However, an argument can be made that this experience better reflects actual dilemmas dietetic students will encounter during their careers as registered dietitians. Porter et al. (2019) asserts that students can benefit from practicing with real patients, stating that "real patients [are] able to contribute authenticity to curricular decisions." Additionally, another study advocates that this educational strategy "enables students to discover the nuances of dietetic practice, practice people $\square$ related skills, and develop confidence in those skills that are crucial to practice" (Swanepoel, Tweedie, \& Maher, 2016). While simulated patients can provide beneficial practice for students, they may not always provide students with 
authentic counseling experiences that real patients are able to. Among the limited selection of studies that have observed the outcomes of dietetic students working with real patients, multiple studies concluded that simulated and real patients provide students with equally effective learning experiences and offer different educational benefits (Porter et al., 2019; Schwartz et al., 2014). Despite findings in current literature, simulated patients are still widely used over real patients in nutrition counseling training.

Therefore, the purpose of this study was to explore the educational advantages real patients can offer dietetic students. In addition, this study observed the impact of training with real patients on dietetic students' nutrition counseling confidence. This study aimed to document if a sample of dietetic students preferred to work with real patients or simulated patients during nutrition counseling training. This was evaluated by conducting interviews with a group of dietetic students who had previously provided nutrition counseling to both simulated and real patients during their academic careers.

Incorporating the findings from this study into the literature helps fill the gap represented by the lack of studies that have observed the outcomes and advantages of utilizing real patients as an educational tool for nutrition counseling training. This study sought to offer further insight to the existing body of literature regarding how real patients may contribute to a dietetic student's education in ways that simulated patients may not. To fill this gap in the literature, the following research questions were generated: 1) How do dietetic students perceive their nutrition counseling confidence after counseling real patients? and 2) What are the educational opportunities of dietetic students training with real patients? and 3) How do students describe their preference for working with real patients or simulated patients during nutrition counseling training? 


\section{Methods}

\section{Participants and Recruitment}

This study employed a purposive sampling technique to recruit participants for individual, semi-structured interviews. Purposive sampling is widely used in qualitative research due to its ability to recruit informants who have abundant knowledge concerning the research topic (Creswell, 2013). Due to restrictions set forth by the Coronavirus 2019 pandemic, all interviews and recruitment strategies were conducted virtually via Zoom and email, respectively. Prospective participants were selected from a group of dietetic students who had previously volunteered as nutrition counselors with Nutrition Mission, a nutrition counseling program at a midsize university in the Midwest region of the United States. Additionally, all participants recruited for the study were over the age of 18 and had declared majors in dietetics. Students eligible for the study were sent a recruitment email outlining the study's purpose, methodology, and associated risks. Students who agreed to participate in the study were sent a follow-up email containing a link to a Zoom meeting for their virtual interview. Before answering any interview questions, participants were required to provide written informed consent. All data collected from participants remained confidential and anonymous throughout the course of the study. This study was approved by the Institutional Review Board.

\section{Nutrition Counseling Program}

Nutrition Mission is a nutrition counseling program at a university in the Midwest region of the United States. This program was created several years ago with a mission to provide a safe and convenient space for college students enrolled at the university to receive free nutrition counseling. The program utilizes undergraduate dietetic students as nutrition counselors. Dietetic students are able to practice their nutrition counseling skills and earn volunteer hours through the 
program. At the beginning of each academic semester, all undergraduate dietetic students with a class rank of junior or senior are invited to volunteer for the program. Additionally, undergraduate students of any major are invited to participate as clientele for the program.

Clients can schedule nutrition counseling appointments by emailing the program coordinator with their preferred meeting time. The program coordinator pairs the client with a dietetics student whose availability coincides with the time and date the client prefers. From there, clients are asked to complete a three-day diet recall prior to their appointment. The dietetic students calculate and analyze diet recall data using Food Processor, a nutritional analysis software program that calculates calories and activity levels for weight gain, loss, and dietary needs. During nutrition counseling appointments, dietetic students sit with their clients and review diet recall data, provide nutrition education, and discuss effective strategies to help clients meet their nutrition-related goals. Following their initial nutrition counseling session, clients can schedule as many follow-up appointments as they would like.

\section{Data Collection}

Qualitative data was collected through semi-structured interviews with individual participants. This interview style is frequently used in healthcare research as it provides the researcher with structured guidance while maintaining flexibility for new avenues of exploration (Mogre, Stevens, Aryee, Amalba, \& Scherpbier, 2018). The open-ended interview questions were formulated to gain insight into dietetic students' perspectives of their experiences counseling real patients and to understand how this experience impacted students' confidence in their ability to provide effective nutrition counseling. The questions also aimed to document dietetic students' opinions regarding differences between counseling real patients and counseling simulated patients. An outline was created to align interview questions with the study's research 
questions to ensure relevant data would be collected through interviews with participants (see Appendix B for interview guide and Appendix C for outline).

Interviews lasted approximately 15-30 minutes and were conducted by the primary investigator via Zoom, a virtual meeting platform. The interviews provided a space for participants to talk about their experiences volunteering with Nutrition Mission and to discuss their opinions regarding advantages and disadvantages of counseling real and simulated patients. During interviews with participants, the primary investigator asked the same series of questions and probed for clarification or elaboration of participants' responses as needed. At the end of their interviews, participants were given an opportunity to expand on previous responses and contribute additional information that was not addressed through the interview questions.

\section{Data Analysis}

Interviews were audio-recorded and manually transcribed by the primary investigator. To ensure anonymity, interview transcripts were stored securely in a password protected file on the research advisor's computer. To further establish trustworthiness and contribute to this study's credibility, study participants were invited to participate in member checks prior to the commencement of data analysis (Forero et al., 2018; Lincoln \& Guba, 1985). This provided an opportunity for participants to review and clarify data collected from their individual interviews.

Qualitative data analysis occurred using a grounded theory approach. Grounded theory describes an approach for developing theory that is "grounded in data systematically gathered and analyzed" (Corbin \& Strauss, 2014). This approach involves three different stages of analysis: open coding, axial coding, and selective level coding. At the start of open coding for this study, the primary investigator and a member of the research committee team-coded one transcript in parallel to develop an approach to analyzing the data that fit the research questions 
and could be consistently applied to all transcripts. The researchers agreed on a small set of initial codes that appeared well suited to both research questions and data at hand. Furthermore, the researchers ensured the initial codes aligned their approaches before returning to parallel coding and discussing the codes again. From there, the primary investigator completed the remaining data analysis individually. Throughout the entire process, the primary investigator kept an analytical log to record each step of data analysis. The log is not attached in the appendix, but is available upon request.

During the remainder of the open coding stage, interview transcripts were conceptualized and coded. A list of code definitions was created to help organize and track code descriptions. Codes that maintained similar definitions were merged together. For example, the codes "more promotion" and "increase advertising" were combined to form the code "advertise." The consolidated codes were examined for connections during the axial coding stage (Foley \& Timonen, 2015). Codes that shared connections were placed into loosely structured categories. From there, the loose categories were revised and narrowed down to core categories. Throughout open and axial coding, memos were created to keep track of moments of clarity. The memos were then utilized to help solidify research findings in selective level coding. During selective level coding, the final stage of analysis, core categories were evaluated to identify overarching themes (Foley \& Timonen, 2015). A member of the research committee served as a peer reviewer to further examine the research findings (Kelly, Sadeghieh, \& Adeli, 2014). The code map portrayed in Figure 1 provides an outline of the initial tags, final codes, core categories, and major themes that emerged from the data. 


\section{Findings}

\section{Overview}

Six dietetic students who had previously participated in the Nutrition Mission program gave consent to be interviewed for this study. Themes that emerged from students' responses to interview questions were (1) Real counseling experience aids in career preparation, (2) Opportunity to increase confidence, (3) Simulated practice is comfortable, but limited, and (4) Nutrition Mission lacking attendance. Detailed descriptions and distinctive quotes from transcripts have been used to illustrate notable components of the themes.

\section{Real Counseling Experience Aids in Career Preparation}

Dietetic students believed that counseling real patients better prepared them for careers in dietetics. Many students explained that having authentic interactions with clients who they did not know personally provided them with a sense of professionalism during counseling sessions. Student D explained that practicing with real patients better resembles professional counseling sessions, stating, "Not having familiarity with the person beforehand better reflects what real counseling sessions will be like during my future career endeavors." Furthermore, Student E discussed that working with real patients improved her professional communication skills and said, "I'm currently working as a diet clerk, and I feel like learning how to counsel real people during Nutrition Mission helped me better communicate with patients at the hospital."

A previous study conducted in a similar setting reported no significant differences between using simulated patients and real patients as effective nutrition counseling teaching strategies (Schwartz et al., 2014). However, other studies emphasized that counseling real patients provides students with an opportunity to enhance their nutrition counseling skills in a professional learning environment (Porter et al., 2019; Swanepoel et al., 2016). Porter et al. 
(2019) discovered that dietetic students perceived simulated and real counseling experiences to be useful for their learning. Only the students who practiced their counseling skills with real patients, however, expressed learning new counseling techniques and improving people-related skills. Additionally, Swanepoel et al. (2016) found that students who counseled real patients reported a heightened sense of professionalism following their experiences.

\section{Opportunity to Increase Confidence}

All students interviewed for this study indicated their confidence in their ability to provide effective nutrition counseling increased as a result of counseling real patients through Nutrition Mission. Student B expressed, "Getting the experience of being able to do the real thing made me a lot more confident in my skills and ability to help people." Student E revealed that counseling a real patient aided in overcoming nerves, stating, "When I actually did it, I realized it was not a big deal and I felt silly for being so nervous." Student D commented, "I had just declared my major in dietetics when I started volunteering for the program, so being able to successfully counsel real patients made me feel more confident in my career choice." Swanepoel et al. (2016) demonstrated similar findings. The results of this study revealed that students who practiced nutrition counseling with real patients at a university health clinic reported increased confidence in their ability to establish rapport with clients and develop nutrition counseling skills that are crucial to professional practice.

\section{Simulated Practice is Comfortable, but Limited}

All students interviewed for this study stated they provided nutrition counseling to simulated patients through curricular activities during their academic careers. While a few students discussed positive attributes of practicing with simulated patients, most students revealed disadvantages of simulated practice. A few positive aspects described by students were 
the ability to ask for feedback, practicing with friends, and planning out counseling sessions ahead of time. Most students that mentioned these positive attributes of simulated practice discussed that practicing with simulated patients is a helpful starting point. Student B stated, "It's helpful to start out by counseling simulated patients since there is less pressure involved." Furthermore, Student F expressed, "I think this method can help give students an idea of how a typical counseling session flows. Once students feel more comfortable, they could start counseling real patients in order to have real-life interactions with actual people."

A common disadvantage expressed by students was that simulated practice is difficult to take seriously. Student A commented that practicing with real patients "replicates a real life counseling experience better than a class project with a pretend counseling session." Student C explained, "It's not going to be the same when someone is simulating it...when you know the person you're talking to, you can tell they're clearly acting. I think there is a benefit to using simulated patients initially to watch and learn from other classmates, but nothing is truly going to replicate the real thing." Overall, several students discussed that simulated practice is useful when students are first learning how to provide nutrition counseling, but may not be as effective as real practice in the long run.

\section{Nutrition Mission Lacking Participants}

An unexpected finding that emerged from the data set were students' coinciding opinions about the weaknesses of the Nutrition Mission program. Almost every student interviewed expressed that Nutrition Mission could be vastly improved if more student participants signed up to receive nutrition counseling through the program. Several students proposed that it should be offered as an extra credit opportunity. Others discussed that students with health-related majors should be encouraged to sign up. Student A stated, "I know a lot of nursing majors who may 
think the program is interesting." Most students agreed the program was a beneficial resource for dietetic students when they were able to gain experience counseling real patients. Student D concluded, "Getting the word out about the program and encouraging students to sign up would help a lot. I thought it was a valuable thing to do as a dietetics student, I just don't think that many people knew about it." Observing students' experiences with the shortcomings of the Nutrition Mission program provides an opportunity for future researchers to explore strategies regarding program enhancement.

\section{Discussion}

This study aimed to explore the impact of utilizing real patients during nutrition counseling training. The findings provide insight into advantages real patients can offer dietetic students and the educational opportunities of incorporating both simulated and real counseling experience into dietetics curriculum. Dietetic students interviewed for this study perceived their real counseling experiences as beneficial for their professional and personal growth. A few students revealed positive aspects of simulated practice, such as feeling less pressure during mock counseling sessions. However, most students expressed that simulated practice limits their ability to practice nutrition counseling techniques in an authentic setting. Overall, all students interviewed for this study expressed a preference for training with real patients over simulated patients.

\section{Real Counseling Experience}

The findings from this study suggest that practicing nutrition counseling with real patients can help dietetic students develop confidence and professional skills that are crucial to the career field. Dietetic students interviewed for this study expressed their nutrition counseling confidence increased following their counseling sessions with patients they did not know 
personally. Additionally, some students revealed that counseling real patients helped them enhance their professional communication skills and rapport with clients. Students' perceptions that counseling real patients increased their confidence and enhanced their professional skillset are similar to those expressed by other dietetic students from previous studies (Horacek, Salomón, \& Nelsen, 2007; Porter et al., 2019; Swanepoel et al., 2016).

\section{Simulated Counseling Experience}

When students were asked about their perceptions of simulated practice, many discussed that simulated counseling sessions can be useful, but only in specific contexts. The benefits of simulated practice most commonly addressed by students were the ability to receive feedback from instructors, the involvement of less pressure, and simulations being a good starting point. Among the dietetic students who discussed advantages of simulated practice during their interviews, all students agreed this teaching strategy is best utilized for students new to nutrition counseling. Furthermore, these students asserted that real counseling practice should be implemented after students are comfortable with simulated practice to give dietetic students a more authentic counseling experience. Past literature has supported that simulated nutrition counseling practice is an effective teaching strategy for students that presents a lower risk than real counseling practice (Buchholz et al., 2020; Schwartz et al., 2014). However, other studies have highlighted multiple ways that real counseling practice may be more effective than simulated practice.

Recent literature proposed that simulated practice may hinder dietetic students' abilities to apply authentic nutrition counseling techniques and decision-making skills to counseling sessions (Porter et al., 2019). Additionally, Gibson \& Davidson (2016) discovered that simulated nutrition counseling sessions had a limited impact on dietetic students' communication and 
professional skill development when compared to real counseling sessions. Dietetic students interviewed for this study mimicked these concerns in their interviews. Several students explained that simulated practice is difficult to take seriously when training with peers. Furthermore, these students revealed they were more focused on getting a decent grade on the assignment rather than trying to enhance their nutrition counseling skills through curricular simulated counseling experiences. The experiences of participants in this study and previous literature provide evidence that practicing nutrition counseling with real patients offers students specific advantages that simulated practice may be lacking. Incorporating both simulated and real nutrition counseling experience into dietetics curriculum should be encouraged to provide students with well-rounded opportunities to develop skills essential for professional practice.

\section{Limitations and Strengths}

Some notable limitations were present in this study. First, a small sample size was used for this study since recruitment was limited to dietetic students who had participated in the same nutrition counseling program at the same university. Furthermore, the participant sample may not be representative because dietetic students in favor of counseling real patients could have been more inclined to volunteer as nutrition counselors for the program. It is important to point out the potential sampling bias this study may have generated and to note that dietetic students attending other universities may have differing views on practicing nutrition counseling with real and simulated patients.

The potential sampling bias may, however, be described as a strength in qualitative research (Mogre et al., 2018). On account of their experiences counseling real patients, students recruited for this study can be considered rich sources of information that support the study's purpose. The purpose of this study may not have been fulfilled if a random sampling technique 
were employed in place of a purposive sampling technique. Additionally, as a measure to reduce interviewer bias that may impact students' opinions during the semi-structured interviews, the interviews were limited to questions and clarifications. Students were probed for more information only when necessary, and the interviewer refrained from expressing their own opinions to avoid influencing dietetic students' responses. Furthermore, all opinions expressed by dietetic students were taken into consideration when themes were derived from the data.

\section{Future Research}

A component of the Nutrition Mission program addressed in the findings of this study is the integration of other health majors as program clients. While the present study did not observe this particular aspect of the Nutrition Mission program, past studies have shown that providing opportunities for interdisciplinary health majors and dietetic students to train together promotes interprofessional behavior among these groups (Caines, Asiedu, Dugdale, \& Wu, 2018). Moreover, current literature has supported that counseling real patients can benefit dietetic students and patients alike. Porter et al. (2019) presented that training with real patients not only improved the dietetic students' nutrition counseling skills, but the counseling sessions also improved the patients' progress towards their health-related goals. While this study did not observe patients' views on nutrition counseling sessions with dietetic students, future studies should investigate the perspectives of patients along with students. Understanding further advantages of using real patients in nutrition counseling training can promote nutrition educators to enhance dietetic students' learning experiences.

\section{Conclusion}

This study aimed to explore the impact of utilizing real patients during nutrition counseling training. The findings from this study suggest that counseling real patients can offer 
dietetic students specific advantages that can aid in their development as dietetic professionals. This study contributes new information for a growing area of dietetics curriculum and strengthens existing literature surrounding the need for further inclusion of real nutrition counseling experience into dietetic students' education. Integrating real counseling practice into dietetics curriculum can enhance the learning experiences of dietetic students and the nutrition $\square$ related health of the individuals they will serve throughout their academic and professional careers (Morgan, Campbell, \& Reidlinger, 2019). Incorporating the findings from this study into the literature helps fill the gap represented by the lack of studies that have observed the outcomes and advantages of utilizing real patients as an educational tool in nutrition counseling training. 
Figure 1. Code Map Illustrating Findings from Interviews with Dietetic Students.

\section{Themes}

$\begin{array}{cccc}\text { Real Counseling } & \text { Opportunity to } & \text { Simulated Practice is Comfortable, } & \text { Nutrition } \\ \text { Experience Aids } & \text { Increase } & \text { but Limited } & \text { Mareer } \\ \text { Preparation } & \text { Confidence } & & \text { Participants }\end{array}$

Categories

Career-Like Personal Growth Laid-Back Limitations

Strategies to

enhance

Nutrition

Mission

\section{Codes}

\begin{tabular}{|c|c|c|c|c|}
\hline $\begin{array}{l}\text { Authentic } \\
\text { interactions }\end{array}$ & $\begin{array}{l}\text { Building } \\
\text { confidence }\end{array}$ & $\begin{array}{l}\text { Practicing with } \\
\text { friends }\end{array}$ & $\begin{array}{c}\text { Hard to take } \\
\text { seriously }\end{array}$ & $\begin{array}{c}\text { Incorporate othe } \\
\text { health majors }\end{array}$ \\
\hline $\begin{array}{l}\text { In-real-time } \\
\text { responses }\end{array}$ & $\begin{array}{l}\text { Becoming a } \\
\text { leader }\end{array}$ & Low expectations & $\begin{array}{l}\text { Trouble with } \\
\text { navigating }\end{array}$ & Advertise \\
\hline lizing dietary & Newiound & $\begin{array}{l}\text { Can ask for } \\
\text { feedback }\end{array}$ & conversations & $\begin{array}{l}\text { Offer as extra } \\
\text { credit }\end{array}$ \\
\hline lysis software & $\begin{array}{l}\text { preference for } \\
\text { real counseling }\end{array}$ & Pre-planned & $\begin{array}{l}\text { Going through the } \\
\text { motions }\end{array}$ & \\
\hline $\begin{array}{c}\text { Sense of } \\
\text { rofessionalism } \\
\text { Unfamiliar }\end{array}$ & $\begin{array}{c}\text { Improving } \\
\text { communication } \\
\text { skills }\end{array}$ & $\begin{array}{l}\text { Less pressure to } \\
\text { be perfect }\end{array}$ & $\begin{array}{l}\text { Not beneficial for } \\
\text { long-term use }\end{array}$ & tive \\
\hline & $\begin{array}{l}\text { Overcoming } \\
\text { nerves }\end{array}$ & & & \\
\hline
\end{tabular}

\section{Tags}

Extracurricular Real experience
Curricular Mock experience
Jumping off point Underutilized 


\section{CHAPTER II: EXTENDED REVIEW OF THE LITERATURE}

The purpose of this literature review was to evaluate pre-existing literature to gain an understanding of research findings that evaluated nutrition counseling's role in managing chronic disease and examined registered dietitians' advanced nutrition counseling competence.

Additionally, this literature review aimed to identify current research gaps regarding optimal nutrition counseling training techniques to aid in dietetic students' education.

\section{Nutrition Counseling's Role in Managing Chronic Illness}

Chronic illness is the leading cause of death in the United States (Cohen \& Knopman, 2018). Numerous chronic illnesses, including type 2 diabetes, cardiovascular disease, cancer, and obesity, are directly related to dietary consumption (Murray et al., 2013). Diet-related chronic disease has been defined as a preventable illness for which poor diet quality is an important risk factor (Flynt \& Daepp, 2015). Nutrition counseling helps patients form positive dietary habits, and is a vital component of managing, and preventing, diet-related chronic disease.

Nutrition counseling is a process designed to create individualized action plans tailored to help patients establish goals and motivation to improve their overall health status (Schwartz, Rothpletz-Puglia, Denmark, \& Byham-Gray, 2014). During an initial nutrition counseling session, typically performed by a registered dietitian or certified nutrition consultant, the counselor may ask patients about their medical history, current medications, reason for wanting to see a nutrition counselor, and lifestyle habits. Generally, nutrition counselors use the initial counseling session to establish rapport with a new patient. A nutrition counselor may also review food logs recorded by patients prior to the first session, and help patients establish nutritionrelated lifestyle goals. Nutrition counselors use subsequent counseling sessions to touch base with patients and revise their individualized care plans as needed. Past research strongly suggests 
that nutrition counseling strategies, such as motivational interviewing, problem solving, and selfmonitoring, promote positive dietary behavior changes essential for decreasing risk factors associated with cardiovascular disease, type 2 diabetes, and obesity (Schwartz et al., 2014). Furthermore, a 2006 study conducted in a small medical office in rural Kentucky concluded that even a single counseling session with a registered dietitian improved clinical outcomes in patients with type 2 diabetes and cardiovascular disease (Gaetke, Stuart, \& Truszczynska, 2006). This study recruited 175 total participants and performed nutrition counseling with 88 participants. Among patients who received nutrition counseling, fasting blood glucose, $\mathrm{HbA1C}$ levels, total cholesterol levels, and triglyceride levels decreased significantly within three months of the counseling session. No significant decreases were observed in these clinical metrics among participants who did not receive nutrition counseling.

A more recent study conducted in 2020 demonstrated similar outcomes in head and neck cancer patients (Ho et al., 2020). This study observed differences between groups of patients who either did or did not receive nutrition counseling during the early stages of their chemotherapy treatment. The results of the study concluded that patients who received nutrition counseling had a significantly higher survival rate and significantly lower chemotherapy incompletion rate than patients who did not receive nutrition counseling. Although conducted nearly 15 years apart, both studies provided strong evidence that nutrition counseling is an essential component of helping patients manage chronic disease. Nutrition counseling's role in helping patients manage and prevent diet-related chronic disease is not only an asset to patients themselves, but to healthcare facilities as well.

Patients battling chronic disease are often malnourished. This is largely due to malnutrition developing as a result of increased requirements associated with a disease state or 
from complications of an underlying illness, such as poor absorption or excessive nutrient losses (Barker, Gout, \& Crowe, 2011). While consequences of malnutrition negatively impact patients with chronic disease, they place additional stress on healthcare facilities caring for patients with chronic disease. Malnourished patients often have higher rates of infections, require more medications, and require greater attention from nursing care. Additionally, these patients are less independent due to muscle loss, and frequently have longer lengths of stay in hospitals. All these issues combined indirectly increase hospital costs associated with treating malnourished patients (Barker et al., 2011). Multiple studies conclude that nutrition counseling has a positive impact on patients battling malnutrition, and, therefore, can aid in lowering hospital costs (Casals et al., 2015; Hernández-Morante, Sánchez-Villazala, Cutillas, \& Fuentes, 2014; Ravasco, MonteiroGrillo, Vidal, \& Camilo, 2005).

A 2015 study evaluated the effects of nutrition counseling in hospitalized malnourished patients. After observing improvements in malnourished patients who received nutrition counseling, this study concluded that nutrition counseling enhanced the patients' nutritional status, quality of life, level of independence, and decreased the number of hospital readmissions (Casals et al., 2015). Another study performed on malnourished patients with colorectal cancer reported that nutrition counseling produced a significantly higher benefit than nutrition supplements on patient outcomes (Ravasco et al., 2005). A similar study conducted several years later observed malnutrition in patients with chronic renal failure. The results of this study concluded that nutrition counseling was effective at preventing, and even treating, malnutrition in patients with chronic renal failure (Hernández-Morante et al., 2014). This study also inferred that improving nutritional status through nutrition counseling can result in a long-term decrease in the mortality and morbidity of malnourished patients battling chronic disease. In addition to 
helping patients manage chronic illness, past literature demonstrates that utilizing nutrition counseling to improve patient outcomes can, simultaneously, benefit healthcare facilities by negating additional costs that arise from complications of chronic disease.

\section{Differences in Nutrition Counseling Competence}

While physicians often deliver nutrition counseling themselves, registered dietitians are considered the sole experts in the field of food and nutrition. In fact, several studies have reported that physicians are underqualified to deliver effective nutrition counseling due to their lack of training and minimal nutrition education during medical school (Baute, Sampath-Kumar, Nelson, \& Basil, 2018; Kris-Etherton et al., 2014; Mogre, Stevens, Aryee, Amalba, \& Scherpbier, 2018). One study asserted that "nutrition education is globally lacking in medical training, despite the fact that dietary habits are a crucial component of disease prevention and treatment" (Baute et al., 2018). Another study that examined methods to advance nutrition education in medical school curriculum concluded there is an urgent need to establish standards for nutrition and physical activity competencies in the education, training, and continuing education for healthcare professionals (Kris-Etherton et al., 2014).

Furthermore, a study published in 2018 evaluated medical students' perspectives on barriers regarding the inadequacy of nutrition education in the medical curriculum. This study performed semi-structured individual interviews with 23 clinical level medical students. Upon analyzing students' responses, this study concluded that students perceived their nutrition education to be inadequate due to a lack of priority for nutrition education within medical school curriculum (Mogre et al., 2018). Additionally, many students revealed there is a lack of faculty to provide nutrition education. To advance nutrition education in medical school curriculum, Mogre et al. (2018) proposed adopting innovative teaching and learning strategies, increasing 
awareness on the importance of nutrition education, reviewing and revising the curriculum to incorporate nutrition education and counseling, and involving registered dietitians in nutrition education tailored for medical students.

Multiple studies have evaluated the outcomes of registered dietitians teaching nutrition education and counseling techniques to medical students and other healthcare professionals (Burch, Crowley, Laur, Ray, \& Ball, 2017; Caines, Asiedu, Dugdale, \& Wu, 2018; Chang, Popovich, Iramaneerat, Smith, \& Lutfiyya, 2008). Caines et al. (2018) observed the effects of nutrition education performed by a registered dietitian on the nutrition counseling skills and confidence of 81 medical students. Medical students were required to complete surveys before and after their nutrition education lecture with the registered dietitian. The objectives of the lecture were to teach medical students basic nutrition guidelines and to give guidance on how to perform effective nutrition counseling with a patient. The results of the study revealed there was a significant increase in medical students' perceived nutrition counseling confidence levels. In addition, $74 \%$ of the study participants found it helpful to work with a registered dietitian (Caines et al., 2018).

Another study observed changes in nutrition counseling competence with 25 pharmacy students following their participation in a nutrition education course. This study presented findings that pharmacy students perceived improvements in their nutrition counseling and clinical nutrition skills as a result of the course (Chang et al., 2008). A similar study conducted several years later demonstrated similar results (Herring, Beckett, Stanton-Robinson, \& Witry, 2018). To evaluate changes in pharmacy students' nutrition knowledge and nutrition counseling comfort levels, this study performed a pre- and post- survey with 40 participants who received the nutrition education intervention. Upon comparing the results of the pre- and post- surveys, it 
was discovered that participants' survey scores revealed statistically significant increases in both total nutrition knowledge and student comfort levels in providing nutrition counseling to patients (Herring et al., 2018).

Burch et al. (2017) evaluated registered dietitians' perspectives on teaching nutrition education to medical students. This qualitative study conducted individual, semi-structured interviews with 24 registered dietitians who had provided nutrition education to medical students. Results of this study demonstrated that participants perceived themselves to be confident in their ability to provide nutrition education to medical students. Additionally, the registered dietitians believed they were the most qualified professionals to administer nutrition education. However, the study's findings also revealed that participants did not feel confident that medical students graduate with adequate nutrition counseling competence. Study participants primarily associated this with the lack of nutrition education and nutrition counseling training available in medical school curriculum (Burch et al., 2017).

Contrary to curriculum tailored for medical students, curriculum for dietetic students entails a variety of nutrition counseling training experiences. Dietetic students are required to complete a set of knowledge requirements for registered dietitian nutritionists, abbreviated as KRDN, specifically affiliated with nutrition counseling. KRDN 3.3 states that, upon completion of their training, graduates are able to "demonstrate counseling and education methods to facilitate behavior change and enhance wellness for diverse individuals and groups" (ACEND, 2016). Curriculum tailored to this requirement often involves a combination of classroom and hands-on learning. Learning effective nutrition counseling skills is a vital constituent of a dietetic student's education. Furthermore, the literature demonstrates that registered dietitians are more qualified to deliver nutrition counseling than other healthcare professionals. That being the case, 
it is essential that dietetic students feel confident and competent in their nutrition counseling skills by the time they complete their training and begin their careers.

\section{Nutrition Counseling Training Techniques}

To ensure dietetic students achieve requisite standards associated with nutrition counseling competence, it is essential that nutrition counseling training techniques offer students optimal opportunities to develop necessary counseling skills. A variety of educational tools for teaching nutrition counseling have been studied across recent decades. Among these tools, many educators employ a combination of peer role playing, case studies, and simulated patients played by actors to help enhance dietetic students' nutrition counseling competence. These educational methods are designed to replace and mimic authentic experiences that would otherwise occur with real patients (Gaba, 2004).

Peer role playing often consists of two classmates taking turns playing the roles of a nutrition counselor and a patient seeking nutrition counseling. Past research suggests that allowing students to experience the perspective of both the clinician and the patient helps improve trainees' understanding of the complexity of the clinician-patient interaction (Bosse et al., 2010). Case-based learning, or case studies, can assist students in finding links between classroom lectures and professional practice while developing crucial skills for careers in the field of dietetics (Harman et al., 2015). Gaba (2004) defines patient simulation as "a techniquenot a technology — to replace or amplify real experiences with guided experiences that evoke or replicate substantial aspects of the real world in a fully interactive manner." Among the aforementioned nutrition counseling training techniques, the impact of utilizing simulated patients to enhance the nutrition counseling skills of dietetic students has been most widely observed in the literature. 
Past studies have exhibited that patient simulations help students gain confidence and increase students' knowledge and preparation to enter the workforce (Buchholz, Vanderleest, MacMartin, Prescod, \& Wilson, 2020; Henry, Duellman, \& Smith, 2009; Miles, Friary, Jackson, Sekula, \& Braakhuis, 2016.) Many studies conducted over the past several decades have implemented similar strategies to observe the impact patient simulations have on dietetic students' nutrition counseling competence (Buchholz et al., 2020; Carroll, Hain, Howell, Crosby, \& Rombeau, 1983; Gibson \& Davidson, 2016). An early 1980s research study observed the effects of using patient simulations to enhance dietetic students' clinical interviewing skills. The findings from this study reported that students who worked with simulated patients were immersed in the simulation to the point where they believed it improved their communication with their patients regarding their clinical concerns (Carroll et al., 1983).

A far more recent study used a similar method to observe alterations in dietetic students' competence in communicating with patients and providing nutrition care. The study recruited undergraduate theatre students to act as the patients of the fourth-year nutrition students. Findings from the study reported that undergraduate dietetic students' communication and nutrition-care scores increased between the first simulation trial and subsequent trials (Buchholz et al., 2020). Although these studies were conducted nearly 40 years apart, they both conclude that patient simulations have been a useful technique in enhancing the nutrition counseling skills of dietetic students. However, while it is clear that patient simulations have a strong success rate, recent studies have concluded that simulations exhibit key limitations in dietetic students' abilities to develop essential communication skills.

A 2016 study observed the effects of using simulated patients to aid in dietetic students' communication skill development (Gibson \& Davidson, 2016). The researchers recruited 215 
upper level dietetic students to participate in the study. Each participant completed two counseling sessions with a simulated patient, and students' communication skills were assessed following each session. The results of the study revealed there was only minimal improvement in dietetic students' communication skills between both counseling sessions (Gibson \& Davidson, 2016). Furthermore, this study concluded that the use of simulated patients as an educational strategy should be taken into consideration when comparing the substantial resources needed to the strategy's limited impact on dietetic students' communication skill development.

Simulated patients fabricate their health conditions for educational purposes. This may hinder dietetic students' abilities to accurately design individualized care plans if the simulated patient does not have actual goals they want to achieve, or if students have difficulty assessing a simulated patient's fabricated desire to change. Furthermore, simulated patients typically follow a rehearsed script, which may limit dietetic students' development of essential communication skills (Gibson \& Davidson, 2016; Schwartz et al., 2014). Porter et al. (2019) asserts that students can benefit from practicing with authentic patients, explaining that "real patients [are] able to contribute authenticity to curricular decisions." While students can still enhance their nutrition counseling skills through simulated practice, patient simulations may not always replicate an authentic counseling experience.

\section{Nutrition Counseling Training with Real Patients}

Although outcomes of dietetic students practicing nutrition counseling with real patients have not been widely observed in the literature, few studies have examined the impact real patients can have on dietetic students' nutrition counseling competence. Porter et al. (2019) presented findings that dietetic students can benefit from practicing with both simulated and real patients. Furthermore, the researchers concluded that real patients offer specific advantages that 
simulated patients do not, such as authenticity in patient interactions. To evaluate this subject further, this study reviewed past literature that examined key differences in dietetic students' counseling and communication skill development following their experiences working with simulated and real patients.

One study from the review utilized simulated patients that were played by actors pretending to have body weight concerns with health-related risks. A separate study observed in the review utilized real patients who were overweight/obese and seeking nutrition counseling services. Upon comparing the results of these studies, Porter et al. (2019) discovered that dietetic students perceived both the simulated and real counseling experiences to be useful for their learning. However, only the students who practiced their counseling skills with real patients expressed learning new counseling techniques and improving rapport with patients through their experiences. Additionally, the findings demonstrated that students who worked with real patients perceived themselves benefiting from having the ability to see their patients gradually progress throughout the nutrition counseling process (Porter et al., 2019).

A recent study explored the impact of counseling real patients in a university $\square$ based health clinic on dietetic students' perceived confidence levels and development of skills needed for professional practice (Swanepoel, Tweedie, \& Maher, 2016). The university health clinic utilized for this study was designed to provide nutrition and dietetic students with an experiential learning opportunity to practice diet history interviewing and nutrition counseling skills with real clients. This study conducted qualitative interviews through focus groups with 13 dietetic students to observe students' perceived nutrition counseling and professional skill development. The results of the study exhibited that participating in an authentic learning environment was viewed positively by students. Additionally, dietetic students believed the real counseling 
experience allowed them to develop deeper nutrition counseling confidence levels and a heightened sense of professionalism (Swanepoel et al., 2016). Ultimately, this study concluded that dietetic curriculum should provide students with authentic learning experiences in a safe environment, advocating that this educational strategy "enables students to discover the nuances of dietetic practice, practice people $\square$ related skills, and develop confidence in those skills that are crucial to practice" (Swanepoel et al., 2016).

A 2019 systematic review of the literature aimed to understand dietetic students' perceived preparedness to enter the workforce based on their curricular experiences (Morgan, Campbell, \& Reidlinger, 2019). This study concluded that dietetic students undertake a hefty transformational journey throughout the course of their education. To help students overcome obstacles encountered along this journey, Morgan et al. (2019) proposed that advanced educational strategies, such as collaboration across dietetics curriculum, can enhance the learning experiences of future dietetic students and the nutrition $\square$ related health of the individuals they will serve throughout their professional careers. Porter et al. (2019) concludes that collaboration with real patients is an educational strategy that should be more widely considered since multiple studies have demonstrated benefits in both student and patient outcomes when dietetic students are able to practice nutrition counseling and communication skills with real patients.

\section{Gap in the Literature}

Studies that examine the impact simulated patients have on dietetic students' nutrition counseling confidence levels and skill development have been widely observed in the literature. Among this selection, some studies have discovered that simulated patients can provide beneficial practice for students, but they may not always provide students with the authentic counseling experiences that real patients are able to (Porter et al., 2019). However, few studies 
have observed the outcomes of dietetic students utilizing real patients during nutrition counseling training. To fill this gap in the literature, this study conducted semi-structured, individual interviews with dietetic students to inquire about their experiences following their counseling sessions with real patients.

\section{Conclusion}

Exploring the impact counseling real patients has on dietetic students may influence the way nutrition counseling training is administered to future nutrition and dietetic students.

Furthermore, determining the educational advantages of counseling real patients can be used to advocate for curriculum to provide students with equal opportunities to receive nutrition counseling training with both simulated and real patients. Incorporating the findings from this study into the literature helps fill the gap represented by the lack of studies that have observed the outcomes and advantages of utilizing real patients as an educational tool in nutrition counseling training. This literature review aimed to provide further insight into nutrition counseling's role in managing chronic illness, registered dietitians' nutrition counseling competence, and how real patients can contribute to dietetic students' nutrition counseling skill development in ways that simulated patients may not. 


\section{REFERENCES}

ACEND. (2016, July 29). ACEND Accreditation Standards for Nutrition and Dietetics Didactic Programs (DPD). Retrieved August 10, 2020, from https://www.eatrightpro.org/acend/accreditation-standards-fees-and-policies/2017standards

Barker, L. A., Gout, B. S., \& Crowe, T. C. (2011). Hospital malnutrition: prevalence, identification and impact on patients and the healthcare system. International Journal of Environmental Research and Public Health, 8(2), 514-527. https://doi.org/10.3390/ijerph8020514

Baute, V., Sampath-Kumar, R., Nelson, S., \& Basil, B. (2018). Nutrition education for the health-care provider improves patient outcomes. Global Advances in Health and Medicine, 7, 2164956118795995. https://doi.org/10.1177/2164956118795995

Bosse, H. M., Nickel, M., Huwendiek, S., Jünger, J., Schultz, J. H., \& Nikendei, C. (2010). Peer role-play and standardised patients in communication training: a comparative study on the student perspective on acceptability, realism, and perceived effect. BMC Medical Education, 10, 27. https://doi.org/10.1186/1472-6920-10-27

Buchholz, A., Vanderleest, K., MacMartin, C., Prescod, A., \& Wilson, A. (2020). Patient simulations improve dietetics students' and interns' communication and nutrition-care competence. Journal of Nutrition Education and Behavior, 52(4), 377-384. https://doi.org/10.1016/j.jneb.2019.09.022

Burch, E., Crowley, J., Laur, C., Ray, S., \& Ball, L. (2017). Dietitians' perspectives on teaching nutrition to medical students. Journal of the American College of Nutrition, 36(6), 415421. https://doi.org/10.1080/07315724.2017.1318316 
Caines, L., Asiedu, Y., Dugdale, T., \& Wu, H. (2018). An interprofessional approach to teaching nutrition counseling to medical students. MedEdPORTAL : The Journal of Teaching and Learning Resources, 14, 10742. https://doi.org/10.15766/mep_2374-8265.10742

Carroll, J., Hain, W., Howell, B., Crosby, L., \& Rombeau, J. (1983). Using simulated patients to teach clinical nutrition. Journal of Nutrition Education, 15(3), 84-87. https://doi.org/10.1016/S0022-3182(83)80003-X

Casals, C., García-Agua-Soler, N., Vázquez-Sánchez, M. Á., Requena-Toro, M. V., PadillaRomero, L., \& Casals-Sánchez, J. L. (2015). Randomized clinical trial of nutritional counseling for malnourished hospital patients. Revista Clinica Espanola, 215(6), 308314. https://doi.org/10.1016/j.rce.2015.02.012

Chang, L., Popovich, N. G., Iramaneerat, C., Smith, E. V., \& Lutfiyya, M. N. (2008). A clinical nutrition course to improve pharmacy students' skills and confidence in counseling patients. American Journal of Pharmaceutical Education, 72(3), 66. https://doi.org/10.5688/aj720366

Cohen, D.A. and Knopman, D.S. (2018). Existing regulatory approaches to reducing exposures to chemical $\square$ and product $\square$ based risk and their applicability to diet $\square$ related chronic disease. Risk Analysis, 38, 2041-2054. https://doi.org/10.1111/risa.13002

Corbin, J. M., \& Strauss, A. (2014). Basics of Qualitative Research (4th ed.). Thousand Oaks, CA: Sage Publications.

Creswell, J. W. (2013). Qualitative Inquiry and Research Design: Choosing Among Five Approaches. Thousand Oaks, CA: Sage Publications. 
Flynt, A., \& Daepp, M. I. (2015). Diet-related chronic disease in the northeastern United States: a model-based clustering approach. International Journal of Health Geographics, 14, 25. https://doi.org/10.1186/s12942-015-0017-5

Foley, G., \& Timonen, V. (2015). Using grounded theory method to capture and analyze healthcare experiences. Health Services Research, 50(4), 1195-1210. https://doi.org/10.1111/1475-6773.12275

Forero, R., Nahidi, S., De Costa, J., Mohsin, M., Fitzgerald, G., Gibson, N., McCarthy, S., \& Aboagye-Sarfo, P. (2018). Application of four-dimension criteria to assess rigour of qualitative research in emergency medicine. BMC Health Services Research, 18(1), 120. https://doi.org/10.1186/s12913-018-2915-2

Gaba D. M. (2004). The future vision of simulation in health care. Quality \& Safety in Healthcare, 13 Suppl 1(Suppl 1), i2-i10. https://doi.org/10.1136/qhc.13.suppl_1.i2

Gaetke, L. M., Stuart, M. A., \& Truszczynska, H. (2006). A single nutrition counseling session with a registered dietitian improves short-term clinical outcomes for rural Kentucky patients with chronic diseases. Journal of the American Dietetic Association, 106(1), 109-112. https://doi.org/10.1016/j.jada.2005.09.051

Gibson, S. J., \& Davidson, Z. E. (2016). An observational study investigating the impact of simulated patients in teaching communication skills in preclinical dietetic students. Journal of Human Nutrition and Dietetics : The Official Journal of the British Dietetic Association, 29(4), 529-536. https://doi.org/10.1111/jhn.12352 
Harman, T., Bertrand, B., Greer, A., Pettus, A., Jennings, J., Wall-Bassett, E., \& Babatunde, O. T. (2015). Case-based learning facilitates critical thinking in undergraduate nutrition education: students describe the big picture. Journal of the Academy of Nutrition and Dietetics, 115(3), 378-388. http://doi.org/10.1016/j.jand.2014.09.003

Henry, B., Duellman, M., \& Smith, T. (2009). Nutrition-based standardized patient sessions increased counseling awareness and confidence among dietetic interns. Topics in Clinical Nutrition, 24(1), 25-34. https://doi.org/10.1097/TIN.0b013e3181978050

Hernández-Morante, J. J., Sánchez-Villazala, A., Cutillas, R. C., \& Fuentes, M. C. (2014). Effectiveness of a nutrition education program for the prevention and treatment of malnutrition in end-stage renal disease. Journal of Renal Nutrition : The Official Journal of the Council on Renal Nutrition of the National Kidney Foundation, 24(1), 42-49. https://doi.org/10.1053/j.jrn.2013.07.004

Herring, M. S., Beckett, E. A., Stanton-Robinson, C. A., \& Witry, M. J. (2018). What do I eat? Impact of an interactive teaching method for improving pharmacy students' diabetes nutrition knowledge and comfort in providing nutrition counseling. Currents in Pharmacy Teaching \& Learning, 10(7), 918-924. https://doi.org/10.1016/j.cpt1.2018.04.015

Ho, Y. W., Yeh, K. Y., Hsueh, S. W., Hung, C. Y., Lu, C. H., Tsang, N. M., Wang, H. M., Hung, Y. S., \& Chou, W. C. (2020). Impact of early nutrition counseling in head and neck cancer patients with normal nutritional status. Supportive Care in Cancer : Official Journal of the Multinational Association of Supportive Care in Cancer, 10.1007/s00520020-05804-3. 
Horacek, T., Salomón, J., \& Nelsen, E. (2007). Evaluation of dietetic students' and interns’ application of a lifestyle-oriented nutrition-counseling model. Patient Education and Counselling, 68(2), 113-120. https://doi.org/10.1016/j.pec.2007.04.005

Kelly, J., Sadeghieh, T., \& Adeli, K. (2014). Peer review in scientific publications: benefits, critiques, \& a survival guide. EJIFCC, 25(3), 227-243.

Kris-Etherton, P. M., Akabas, S. R., Bales, C. W., Bistrian, B., Braun, L., Edwards, M. S., Laur, C., Lenders, C. M., Levy, M. D., Palmer, C. A., Pratt, C. A., Ray, S., Rock, C. L., Saltzman, E., Seidner, D. L., \& Van Horn, L. (2014). The need to advance nutrition education in the training of healthcare professionals and recommended research to evaluate implementation and effectiveness. The American Journal of Clinical Nutrition, 99(5 Suppl), 1153S-66S. https://doi.org/10.3945/ajcn.113.073502

Lincoln, Y. S., \& Guba, E. G. (1985). Naturalistic Inquiry. Newbury Park, CA: Sage Publications.

Miles, A., Friary, P., Jackson, B., Sekula, J., \& Braakhuis, A. (2016). Simulation-based dysphagia training: teaching interprofessional clinical reasoning in a hospital environment. Dysphagia, 31(3), 407-415. https://doi.org/10.1007/s00455-016-9691-0

Mogre, V., Stevens, F., Aryee, P. A., Amalba, A., \& Scherpbier, A. (2018). Why nutrition education is inadequate in the medical curriculum: a qualitative study of students' perspectives on barriers and strategies. BMC Medical Education, 18(1), 26. https://doi.org/10.1186/s12909-018-1130-5 
Morgan, K., Campbell, K. L., \& Reidlinger, D. P. (2019). Dietetics students' experiences of dietetics workforce preparation and preparedness: a systematic review and qualitative synthesis. Journal of Human Nutrition and Dietetics : The Official Journal of the British Dietetic Association, 32(2), 226-246. https://doi.org/10.1111/jhn.12600

Murray, C. J., Atkinson, C., Bhalla, K., Birbeck, G., Burstein, R., Chou, D., ..., U.S. Burden of Disease Collaborators. (2013). The state of US health, 1990-2010: burden of diseases, injuries, and risk factors. $J A M A, 310(6), 591-608$.

Porter, J., Kellow, N., Anderson, A., Bryce, A., Dart, J., Palermo, C., Volders, E., \& Gibson, S. (2019). Patient involvement in education of nutrition and dietetics students: a systematic review. Nutrients, 11(11), 2798. https://doi.org/10.3390/nu11112798

Ravasco, P., Monteiro-Grillo, I., Vidal, P. M., \& Camilo, M. E. (2005). Dietary counseling improves patient outcomes: a prospective, randomized, controlled trial in colorectal cancer patients undergoing radiotherapy. Journal of Clinical Oncology : Official Journal of the American Society of Clinical Oncology, 23(7), 1431-1438.

https://doi.org/10.1200/JCO.2005.02.054

Schwartz, V., Rothpletz-Puglia, P., Denmark, R., \& Byham-Gray, L. (2014). Comparison of standardized patients and real patients as an experiential teaching strategy in a nutrition counseling course for dietetic students. Patient Education and Counselling, 98(2), 168173. https://doi.org/10.1016/j.pec.2014.11.009

Swanepoel, E., Tweedie, J., \& Maher, J. (2016). Building dietetic student confidence and professional identity through participation in a university health clinic. Nutrition \& Dietetics, 73, 229-234. 


\section{APPENDIX A: CODE MAP FIGURE}

Figure 1. Code Map Illustrating Findings from Interviews with Dietetic Students.

\section{Themes}

Real Counseling Experience Aids in Career Preparation

Categories
Opportunity to Increase

Confidence
Simulated Practice is Comfortable, but Limited
Nutrition

Mission Lacking Participants
Career-Like Personal Growth Laid-Back Limitations

Strategies to

enhance

Nutrition

Mission

\section{Codes}

\section{Authentic}

interactions

In-real-time

responses

Utilizing dietary

analysis software

Sense of

professionalism

Unfamiliar

clientele

$\begin{array}{cc}\text { Building } & \text { Practicing with } \\ \text { confidence } & \text { friends }\end{array}$

Becoming a leader

Newfound preference for real counseling

$$
\begin{gathered}
\text { Improving } \\
\text { communication } \\
\text { skills }
\end{gathered}
$$

\section{Overcoming} nerves

\section{Tags}

\section{Extracurricular}

Real experience
Low expectations

$$
\begin{gathered}
\text { Can ask for } \\
\text { feedback } \\
\text { Pre-planned }
\end{gathered}
$$

Less pressure to be perfect
Hard to take seriously

Trouble with navigating conversations

Going through the motions

Not beneficial for long-term use

\section{Incorporate other health majors}

Advertise

Offer as extra credit

Encourage athletes to join 


\section{APPENDIX B: INTERVIEW GUIDE}

1. I am researching nutrition counseling experiences in the undergraduate setting. Please share the dates or semesters that you volunteered at the Nutrition Mission office on campus.

2. Describe your role in the Nutrition Mission counseling program.

a. PROBE: What tasks did you do as a counselor?

3. Please describe, in detail, a memorable experience you encountered during your counseling sessions.

a. PROBE: if they have trouble remembering, ask what a typical day of volunteering was like.

4. Have you provided nutrition counseling to simulated patients (i.e. pretend patients played by actors or peers) during your academic career?

a. If yes, how, if at all, did counseling real patients differ from counseling simulated patients?

5. Do you feel confident in your ability to provide effective nutrition counseling following your experiences counseling real patients at the Nutrition Mission office?

a. Why do you think that is?

6. How would you describe your preference for working with real patients or simulated patients during nutrition counseling training?

a. PROBE: do you feel each of these educational tools offers different advantages? Please describe why or why not.

7. Would you recommend the use of real patients during nutrition counseling training for dietetic students in the future?

a. Please describe why or why not.

8. What are your suggestions for how Nutrition Mission can be improved for dietetic students in the future?

a. PROBE: if every four-year university could adapt a program similar to Nutrition Mission, do you think this would be a beneficial resource?

9. Is there anything you would like to add or expand upon? 


\section{APPENDIX C: RESEARCH AND INTERVIEW QUESTION OUTLINE}

1) How do dietetic students perceive their nutrition counseling confidence levels after counseling real patients?

- How did counseling real patients differ from counseling simulated patients?

- Do you feel confident in your ability to provide effective nutrition counseling following your experiences counseling real patients at the Nutrition Mission office? Why?

- Would you recommend the use of real patients during nutrition counseling training for dietetic students in the future? Why or why not?

2) What are the educational opportunities of dietetic students training with real patients?

- Describe your role in the Nutrition Mission counseling program.

- Please describe, in detail, a memorable experience you encountered during your counseling sessions.

- Do you feel confident in your ability to provide effective nutrition counseling following your experiences counseling real patients at the Nutrition Mission office? Why?

- Would you recommend the use of real patients during nutrition counseling training for dietetic students in the future? Why or why not?

- What are your suggestions for how Nutrition Mission can be improved for dietetic students in the future?

3) How do students describe their preference for working with real patients or simulated patients during nutrition counseling training?

- Have you provided nutrition counseling to simulated patients (i.e. pretend patients played by actors or peers) during your academic career?

- How would you describe your preference for working with real patients or simulated patients during nutrition counseling training?

4) Miscellaneous

- Please share the dates or semesters that you volunteered at the Nutrition Mission office on campus at Illinois State University.

- What are your suggestions for how Nutrition Mission can be improved for dietetic students in the future?

- Is there anything you would like to add? 


\section{APPENDIX D: CODE DEFINITIONS}

Utilizing dietary analysis software: students described a dietary analysis software used during Nutrition Mission program

Authentic interactions: genuine conversations with real clients

Sense of professionalism: the feeling of being in a career-like situation

Building confidence: boosting confidence in nutrition counseling skills

Extra credit opportunity: program clients could earn extra credit by participating in Nutrition

Mission

Can ask for feedback: asking for feedback from instructors or classmates after mock counseling sessions

Practicing with friends: administering simulated counseling sessions using friends or peers as patients

In-real-time responses: generating on-the-spot answers to real patients' questions

Low expectations: lower expectations to perform well during mock counseling sessions

Becoming a leader: taking on a leadership role when practicing with real patients

Less pressure to be perfect: less pressure to execute counseling session perfectly during mock sessions

Incorporate other health majors: students suggested using other health majors as Nutrition

Mission program clientele

Encourage athletes to join: students suggested athletes could benefit from counseling services through Nutrition Mission

Newfound preference for real over simulated: students expressed a preference for training with real patients over simulated patients

Advertise: students suggested more advertisement of Nutrition Mission program could help get more participants interested in the nutrition counseling services

Hard to take seriously: simulated counseling sessions were hard to take seriously

Trouble with navigating conversations: students expressed having trouble navigating

conversations with pretend patients during simulated counseling sessions

Pre-planned: discussions during mock counseling sessions were pre-planned

Not beneficial for long-term use: simulated counseling sessions would not be useful over time as students continue to strengthen their counseling skills

Going through the motions: students stated their simulated counseling sessions for class projects felt like going through the motions to earn a good grade and be finished

Improving communication skills: students improved communication skills during conversations with real patients

Overcoming nerves: real counseling sessions helped students overcome their nerves Unfamiliar clientele: practicing nutrition counseling with unfamiliar patients during real counseling sessions 


\section{APPENDIX E: RECRUITMENT EMAIL}

Subject Line: Nutrition Mission Research Study

Message:

Dear Prospective Participant,

You are receiving this email because you have been invited to participate in a study, titled "Exploring the Impact of Utilizing Real Patients During Nutrition Counseling Training." The purpose of this study is to determine the opportunities and advantages of using real patients as an educational tool for undergraduate dietetic students undergoing nutrition counseling training.

If you choose to participate in this study, you will be asked to participate in a semi-structured qualitative interview held via Zoom. During the interview, you will be asked questions regarding your individual experience providing nutrition counseling to a real patient. In total, your involvement in this study will last approximately 30 minutes to 1 hour.

To participate you must be at least 18 years of age. In addition, you must have previously volunteered as a nutrition counselor for Nutrition Mission at Illinois State University's campus. Your participation in this study will contribute to the body of knowledge relating to nutrition counseling educational approaches and learning outcomes among dietetic students.

If you are eligible for this study and are interested in being interviewed, please contact me directly at arhaye1@ilstu.edu. Additionally, if you would like to learn more about this project, please contact Dr. Julie Schumacher at jmraede@ilstu.edu or 309-438-7031, or Ashlyn Hayes at arhaye1@,ilstu.edu.

Thank you for your time and consideration.

Sincerely,

Ashlyn Hayes 


\section{APPENDIX F: INFORMED CONSENT}

You are being asked to participate in a research study conducted by Julie Schumacher, Professor, Department of Family and Consumer Sciences and Ashlyn Hayes, Graduate Student, Department of Family and Consumer Sciences. The purpose of this study is to explore the outcomes of utilizing real patients during nutrition counseling training.

\section{Why are you being asked?}

You have been asked to participate because you have previously volunteered with Nutrition Mission at Illinois State University and can provide valuable insight into our study questions regarding your experience counseling real patients. Your participation in this study is voluntary. You will not be penalized if you choose to skip parts of the study, not participate, or withdraw from the study at any time.

\section{What would you do?}

If you choose to participate in this study, you will be asked to participate in a semi-structured qualitative interview. In total, your involvement in this study will last approximately 30 minutes to 1 hour.

\section{Are any risks expected?}

We do not anticipate any risks beyond those that would occur in everyday life.

\section{Will your information be protected?}

We will use all reasonable efforts to keep any provided personal information confidential. Names of individuals will not be utilized. Information that may identify you or potentially lead to reidentification will not be released to individuals that are not on the research team. The research will be disseminated in a manuscript and/or presented at a state or national conference. You will be provided a copy of the final manuscript upon request. However, when required by law or university policy, identifying information (including your signed consent form) may be seen or copied by authorized individuals.

\section{Could your responses be used for other research?}

De-identified data collected from this study may be used for future studies.

\section{Who will benefit from this study?}

This research will benefit future dietetic students by understanding the educational advantages real patients can provide students during nutrition counseling training. Exploring the impact of utilizing real patients as an educational tool can help determine if this approach better prepares students for their careers as registered dietitians.

\section{Whom do you contact if you have any questions?}

If you have any questions about the research or wish to withdraw from the study, contact Julie Schumacher at jmraede@ilstu.edu. If you have any questions about your rights as a participant, or if you feel you have been placed at risk, contact the Illinois State University Research Ethics \& Compliance Office at (309) 438-5527 or IRB@ilstu.edu. 


\section{Documentation of Consent}

By clicking agree, you are giving your consent to participate in the research project. We thank you very much for your willingness to contribute to this important study.

$\square$ I agree to participate.

You will be given a copy of this form for your records. 